\title{
O trabalho manual dos monges (séculos XI-XII): eclesiologia e práticas sociais
}

\author{
The manual work of the monks ( $11^{\text {th }}-12^{\text {th }}$ centuries): ecclesiology and social \\ practices
}

Cécile Caby*

\begin{abstract}
Resumo
O artigo discute a representação Cisterciense do labor monástico. Ele baseia-se primordialmente em fontes polemistas e hagiográficas, tendo o intuito de entender como o discurso monástico sobre as atividades manuais, fora dos muros do mosteiro, se tornou, na Ordem de Cister, um importante elemento de construção identitária. Deseja-se reexaminar o lugar do trabalho manual nos discursos elaborados pelos monges, de modo a interrogar sobre as relações - no seio do monacato e globalmente nas sociedades medievais - entre representação do trabalho e modelo de sociedade. Não é por acaso que o debate monástico se torne agudo e mude de natureza na virada do século XI para o XII, fazendo emergir uma ideia do trabalho que não é mais exclusivamente um instrumento de penitência, mas também um meio positivo de distinção e de hierarquização no caminho da perfeição e, portanto, da salvação. Deste ponto de vista, a virada dos séculos XI e XII seria, através do novo monacato, portadora de um novo paradigma transmitido tanto pelas cartas, quanto pelos textos narrativos, das homilias ou das hagiografias. Assim, se os Cistercienses não romperam com a imagem ascética e penitencial do trabalho, o enriqueceram claramente com um valor positivo, a serviço de uma maior perfeição comunitária.
\end{abstract}

Palavras Chave: Ordem de Cister ; monasticismo; labor ; economia monástica; identidade religiosa.

\begin{abstract}
The article deals with Cistercian representation of monastic labour. It is based primarily on polemical and hagiographical sources in order to understand how monastic discourse about manual activities outside the monastery walls became in the Cistercian order an important element of self-identity construction for the Cistercian order. It is desired to reexamine the place of manual labor in the speeches elaborated by the monks, in order to interrogate the relations - in the heart of monasticism and globally in medieval societies - between work representation and model of society. It is not by chance that the monastic debate becomes acute and changes its nature from the turn of the eleventh to the twelfth century, giving rise to an idea of work that is no longer exclusively an instrument of penance but also a positive means of distinction and hierarchy in the way of perfection and, therefore, of salvation. From this point of view, the turn of the eleventh and twelfth centuries would be, through the new monastic, a new paradigm transmitted by letters, narrative texts, homilies or hagiographies. Thus if the Cistercians do not disrupted the ascetic and penitential image of work, they would enrich with a positive value, in the service of greater communal perfection.
\end{abstract}

Keywords: Cistercian order; monasticism; labour; monastic economy; religious identity

Artigo submetido em 01 de setembro de 2017 e aprovado em 07 de dezembro de 2017. Traduzido do francês para o português pelo Prof. Dr. Bruno Tadeu Salles (UFOP).

\footnotetext{
* Agrégée d'histoire (1990). Ancienne élève de l'École normale supérieure (Ulm-Sèvres), Lettres 87. Ancien membre de l'École française de Rome (1994-1997). Ancien membre junior de I'Institut universitaire de France (2007-2012). Maître de conférence en histoire médiévale à l'université de Nice (1998-2014). País de origem: França. E-mail: cecile.caby@gmail.com
}

Horizonte, Belo Horizonte, v. 15, n. 48, p. 1129-1150, out./dez. 2017 - ISSN 2175-5841 


\section{Introdução}

As considerações seguintes têm por objetivo se interrogar sobre os discursos produzidos pelos Cistercienses e pelos monges contemporâneos que criticaram suas posições quanto ao lugar do trabalho manual no propositum monástico e seu papel na definição da inscrição dos monges na sociedade. A escolha deste tema releva, a princípio, uma oportunidade historiográfica: o trabalho e o valor do trabalho questões muito sensíveis no mundo contemporâneo - relacionam-se com um campo de pesquisa que se apresenta como alvo de uma atenção muito viva, em particular junto aos medievistas ${ }^{1}$, no seio dos quais está em curso uma revisão global da noção de economia nas sociedades medievais, que faz intervir - não sem debates historiadores da Ecclesia e historiadores do mundo campesino ou do comércio (TODESCHINI, 2004; PIRON, 2012; ARNOUX, 2012; BAIN, 2014; BECK, BERNARDI \& FELLER, 2014)².

Se, de minha parte, desejo reexaminar o lugar do trabalho manual nos discursos elaborados pelos monges, isto não é, certamente, para exaltar - do mesmo modo que a historiografia católica liberal - a "missão civilizatória dos cenobitas", nem para reconhecer - com J. Leclerq - na "economia de caridade" dos Cistercienses, uma "economia do desenvolvimento" para nosso tempo, mas para me interrogar sobre as relações - no seio do monacato e globalmente nas sociedades medievais - entre representação do trabalho e modelo de sociedade, em eco eventualmente crítico - ao anúncio de Jacques Le Goff, em um artigo inicialmente aparecido em 1971, segundo o qual: "quaisquer que sejam os motivos disso, o fato que o tipo o mais elevado de perfeição cristã, o monge, se entregue ao trabalho, faz

\footnotetext{
${ }^{1}$ Este trabalho, do qual este artigo propõe uma primeira síntese, nasceu no quadro de uma colaboração com Michel Lauwers (Université de Nice, UMR 7264 CEPAM) e Emmanuel Bain (Université d'Aix-en-Provence, UMR 7303 TELEMME), corresponsáveis por um programa de pesquisa em curso. Eu agradeço a Emmanuel Bain por suas considerações justamente críticas e estimulantes a propósito deste primeiro texto. Desde a entrega deste texto em julho de 2015, o trabalho prosseguiu e os primeiros resultados foram publicados. Ver, particularmente: Emmanuel Bain (2016) et Michel Lauwers (2017a et 2017b).

${ }^{2}$ No que concerne à economia especificamente monástica, serão citados, dentre outros, os trabalhos de Jean-Pierre Devroey (1993); Valentina Toneatto, Peter Cernic e Susi Paulitti (2004); François Menant (2010); Alexis Wilkin (2011); Nicolas Schroeder e Alexis Wilkin (2014).
} 
relançar sobre esta atividade uma parte do prestígio social e espiritual daquele que a pratica"3.

Que os oratores tenham adotado - ou reivindicado o fato de adotar - alguns aspectos do trabalho manual, cujo nome, inclusive, definia o grupo dos laboratores e que algumas ordens tenham, pela busca da humilhação penitencial, procurado submeter alguns milites a um modelo de vida quasi rusticos ${ }^{4}$, não podia, de fato, ser totalmente destituído de sentido. Não é por acaso que o debate sobre este ponto se torne agudo e mude de natureza no mundo monástico na virada do século XI para o XII, fazendo emergir uma ideia do trabalho que não é mais exclusivamente um instrumento de penitência, mas também um meio positivo de distinção e de hierarquização no caminho da perfeição e, portanto, da salvação.

\section{0 trabalho manual e a carta da regra de Bento}

O desenvolvimento de novas formas de vida religiosa - em primeiro lugar aquela dos Cistercienses - é acompanhado, nos anos 1010-1230, de uma produção efervescente de textos que se mostram frequentemente de modo polêmico. Neste contexto, os Cistercienses encarnam, entre outros, o partido do trabalho manual, que contribuem para erigir em assunto central de um debate polimorfo, cujos aspectos eclesiológicos (a hierarquia dos diferentes modos de vida, a função dos monges na Igreja e na sociedade) não devem ser separados de suas expressões muito pragmáticas (o modelo econômico adotado pelos monges, o desenvolvimento e a exploração das terras) (DIMIER, 1982-1987; HOLDSWORTH, 1973; KURZE, 1980; DUBOIS, 1990; BELL, 2000; SCHREINER, 2006) 5. À primeira vista, de fato, os primeiros Cistercienses apresentam seu projeto como um retorno à Regra de Bento

\footnotetext{
3 “Quels qu'en soient les motifs, le fait même que le type le plus élevé de perfection chrétienne, le moine, s'adonne au travail fait rejaillir sur cette activité une partie du prestige social et spirituel de celui qui la pratique". Doravante, Le Goff (1999, p. 115).

${ }^{4} \mathrm{~A}$ expressão quase rústicos provem do sermão 3 para o Natal de Aelred de Rielvaux que, após um elogio da diversidade das formas de vida religiosa, visa à cidade munida de boas observances (pobreza, silencio, obediência) que é a ordem cisterciense, cf. Aelredus (19892012, v. 1, p. 29): Nonne videtis homines saeculi nobiles ad conversionem venientes, lanceas et gladios suos dimittere, et quasi rusticos manibus suis cibum suum operari? 0 tema do miles ao qual se impõe práticas dos laboratores como penitencia e obediência está muito presente no Liber de restauratione Sanci Martini Tornacensis redigido a partir de 1143 por Hériman de Tournai (HERIMANNUS, 2010).

${ }^{5} \mathrm{Um}$ dos raros historiadores a ter tentado reunir estes diferentes aspectos é Martha G. Newman (1996, p. 67-96).
} 
ad litteram de um modo que abraça todas as implicações concretas de tal literalismo (CARIBONI, 2005a). É a este título que se afirma a característica obrigatória do trabalho manual dos monges sobre a base do capítulo 48, 8 da Regra, cujos ecos se encontram, pelo menos, em dois textos normativos dos inícios da Ordem (VOGÜÉ, 1964). Em primeiro lugar, no capítulo 5 dos Instituta generalis capituli (anterior a 1133, segundo Waddell, 1999), a nutrição dos monges deve ser garantida pelo trabalho manual, a cultura das terras e a criação de animais da familia monástica6 . Em segundo lugar, o capítulo 15 do Exordium Parvum que, entre um dossiê documentário e um bloco narrativo, apresentando o relato da morte de Alberic, da eleição de Etienne Harding e das primeiras filiações, inclui um capítulo com acentos normativos, intitulado Instituta monachorum Cisterciensium de Molismo venentium. Trata-se de uma espécie de programa de fidelidade proclamada à regra de Bento, declinado segundo diversas modalidades e que se encontram sistematicamente no coração das polêmicas contemporâneas7: a vestimenta, a alimentação, mas também a interdição de possuir certos tipos de propriedade, certas rendas e certos direitos (notadamente os dízimos) cuja exploração releva, aos olhos dos Cistercienses, de uma forma de roubo que implica a exploração do trabalho alheio (de labore alieno) ${ }^{8}$. A estas interdições, o direito cisterciense responde positivamente, organizando, de modo detalhado, a forma de cobrir a carência de ganhos e reafirmando o dever dos monges que possuem terras e animais de viver disso como verdadeiros pobres de Cristo, isto é, os explorando suis manibus. O trabalho dos monges aparece, assim, aos olhos dos primeiros cistercienses, como o único modo, conforme à regra e a uma concepção autárquica de economia comunitária, de suprir às necessidades da comunidade, mas também de completar as obrigações em matéria de hospitalidade e de esmola inerentes ao propositum monástico, tal como é definido por Bento. Como lembra Isaac de l'Étoile, no sermão

\footnotetext{
${ }^{6}$ Instituta generalis Capituli, capítulo 5: Monachis nostri ordinis debet provenire victus de labore manuum, de cultu terrarum, de nutrimento pecorum: unde et licet nobis possidere ad proprios usus aquas, silvas, vineas, prata, terras a saecularium hominum habitatione semotas, et animalia, praeter illa quae magis solent provocare curiositatem et ostentare in se vanitatem, quam aliquam afferre utilitatem, sicut sunt cervi, grues et caetera hujusmodi. Ad haec exercenda, nutrienda, conservanda, seu prope seu longe non tamen ultra diaetam grangias possumus habere per conversos custodiendas [...].

${ }^{7}$ Exordium Parvum, capítulo 15 (Instituta monachorum cisterciensium). In: Chrisogonus Waddell (1999, p. 434-435).

${ }^{8}$ Sobre isso consultar: Giles Constable (1967) e Cécile Caby (2012).
} 
50 sobre o quadro e o valor do modo de vida cisterciense (conversationis vestrae formulam et vitae auctoritatem), estas funções não excluem o papel penitencial do trabalho - aquele do trabalho de Adão fora do Paraíso - ao qual ele não pode, todavia, ser totalmente reduzido9 ${ }^{9}$ Esta reivindicação não deixou de ser imediatamente reconhecida fora da Ordem, seja para refutá-la ou denegri-la10; ela exerceu igualmente uma influência considerável e duradoura sobre a historiografia que, seguindo os Cistercienses, amplificou, de modo desmesurado, o lugar do trabalho manual na regra de Bento (ROSÉ, 2015).

As questões extremamente conflituosas suscitadas por esta reivindicação podem ser observadas facilmente graças aos textos produzidos no mundo monástico contemporâneo, na polêmica com a interpretação cisterciense da sequela da regra, às vezes com a pretensão de reivindicar exclusivamente para a Ordem Cisterciense o privilégio da pobreza e as prerrogativas decorrentes ${ }^{11}$. Trata-se de um conjunto de textos de um manuseio frequentemente delicado para o historiador em razão das dificuldades de estabelecer uma cronologia segura de suas diferentes partes, de conhecer os modos e os ritmos de sua circulação e, então, a amplitude e o significado dos empréstimos e das influências recíprocas entre os textos, sem mencionar a dificuldade em se apreciar as influências de alguns marcos da literatura patrística sobre o assunto, como o De opere monachoroum de Agostinho (v. 401) ou o livro 10 dos De institutis coenobiorum (v. 420) de Cassiano.

\section{Economia do Dom, trabalho manual e opus Dei}

Mais que muitos outros textos contemporâneos, o prólogo do Libellus de diversis ordinibus et professionibus qui sunt in Ecclesia, redigido na diocese de Liège nos decênios 1130-1140, sublinha, ao mesmo tempo, a vivacidade do debate e

\footnotetext{
${ }^{9}$ Sobre isso, ver a interpretação que Isaac de l'Étoile no sermão 50, §13. In: ISAAC DE L’ÉTOILE, (1987, p. 179-199, p. 188-191); consultar, também, outros textos citados por Anselme Dimier (1982-1987, p. 568).

${ }^{10} \mathrm{Cf}$. Walter Map. De nugis curialium $(1,24)$ p. 37, sobre os cistercienses cuja cupidez nasceu da hospitalidade e a ansiedade de terras da recusa de certos rendimentos.

${ }^{11}$ A este propósito, ver a carta 34 de Pedro o Venerável ao chanceler Aymeric (1133-1137) à propósito da condenação dos Clunisianos de Gigny. In: Giles Constable (1967, p. 112-113); citada por Guido Cariboni (2014).
} 
a característica central que a questão do trabalho manual tinha adquirido. $\mathrm{O}$ autor anônimo, fervoroso partidário de uma harmoniosa diversidade das formas de vida religiosa, anuncia, de fato, uma demonstração que se articula em quatro livros, dos quais, somente o primeiro é conservado (isto é, caso os outros tenham sido redigidos): um primeiro livro que descreve as diferentes ordens e profissões, um segundo consagrado à vestimenta, um terceiro ao regime alimentar e um quarto e derradeiro ao trabalho manual (CONSTABLE \& SMITH, 1972, p. 2) ${ }^{12}$. Ainda que não possuamos este quarto e último livro, o primeiro permite, não menos, que façamos uma ideia do que ele poderia conter, tanto a questão do trabalho aí é essencial, como sublinha sua aparição nos lugares estratégicos da demonstração. Assim, desde o segundo capítulo, a distinção entre Cluniacenses e Cistencienses é posta em termos que opõe, de um lado, a proximidade dos homens, a recepção das esmolas dos fiéis, dos rendimentos dos dízimos e das igrejas e a vida exclusivamente contemplativa, e, de outro, o afastamento das populações, os jejuns, as preces contínuas, a fadiga corporal (corporalis exercitatio, una expressão cujo uso mereceria aprofundamento) (CONSTABLE \& SMITH, 1972, p. 18) ${ }^{13}$.

Muitos outros textos poderiam nos fornecer um resumo comparável dos argumentos em causa e das principais questões do debate. Um dos mais conhecidos é o relato que o monge negro Orderic Vital propôs, antes de 1130, do discurso de Roberto de Molesme que exortava seus monges a seguirem a regra ex integro. De fato, este discurso se inicia precisamente pelo apelo à obrigação do trabalho manual, seguido pelos outros argumentos concernentes à vestimenta e aos dízimos4. O

\footnotetext{
${ }^{12}$ Ad demonstrandum ergo quod istae diversitates professionum Deo placeant accingor, primo loco sermonem habiturus de diversis ordinibus et professionibus monachorum et canonicorum, vel aliorum; secundo, de habitu diverso; tercio de epulis; quarto de la bo re manuum. Consultar, também, Constable e Smith (1972, p. 18): [...] Quos si inter se ipsi monachi de regula contendant, et dicat alter alteri quia laborare in agro debet, et talia indumenta qualia in regula prescripta sunt habere, et illis vel illis epulis secundum regulam uti, intelligat qui hoc dicit et credat si quid a sapientibus aliter quam ipse intelligit visum est, non frustra sed sapienter esse actum [...].

${ }^{13}$ II. De monachis qui iuxta homines habitant, sicut Cluniacenses et eorum similes. Nunc autem ad illos noster sermo dirigatur, qui monachi nomen proprie obtinent, quorum alii a turbis omnino seggregati, vitam Deo placabilem ieiuniis et orationibus et corporali exe rcitatione ducunt, alii iuxta homines in civitatibus et castellis et villis positi, de elemosinis fidelium et reditibus aecclesiarum decimisque sustentatur, soli theoriae operam dantes [...].

${ }^{14}$ [...] Nos fratres karissimi secundum normam sancti patris Benedicti professionem fecimus sed ut michi videtur non eam ex integro tenemus. Multa quae ibi non precipiuntur observamus, et de mandatis eiusdem plura neglegentes intermittimus. Manibus nostris non laboramus, ut sanctos patres fecisse legimus. Si michi non creditis, o amici, legite gesta sanctorum Antonii, Macharii, Pachomii, et ante omnes alios doctoris gentium Pauli apostoli. Abundantem victum et vestitum ex decimis et oblationibus aecclesiarum habemus, et ea quae competunt prebiteris ingenio seu violentia subtrahimus. [...] (In: CHIBNALL, 2002-2003, IV, p. 312-320).
} 
interesse do texto de Orderic é de colocar igualmente em cena a resposta dos monges. Aquela, inteiramente construída sobre a oposição entre trabalho manual e culto divino, justifica a superioridade da opus Dei para os monges pela existência de uma espécie de contrato social ligando, de uma parte, os potentes, fundadores dos mosteiros e doadores de bens que garantem o necessário ad victum et vestitum e, de outra parte, os monges investidos unicamente do labor que lhes é próprio, a saber, o culto divino pro cunctis benefactoris suis ${ }^{15}$. Pode-se comparar este discurso fictício com outras respostas perfeitamente contemporâneas que outros monges negros opuseram aos argumentos reservados, sob a pluma de Orderic, a Roberto de Molesme e que podem ser mais globalmente atribuídos aos Cistercienses: deter-meei em dois deles. O primeiro é a carta 28 endereçada, entre 1127-1128, por Pedro o Venerável, abade de Cluny, a Bernardo, abade de Claraval, cujo oitavo ponto trata especificamente do trabalho manual. Pedro se esforça, principalmente, por responder à questão da relação entre a obrigação do trabalho manual e o respeito à regra, burlando as armadilhas do literalismo reivindicado pelos Cistercienses na sua fidelidade à regra: esta é a razão pela qual ele dedica atenção não ao que a regra diz do trabalho manual, mas sobre o porquê dela o dizer (non tantum quid de opere manuum regula praecipiat, sed etiam quare illud praecipiat). Aquilo permite, de fato, recolocar no centro do debate o combate contra a otiositas monástica, que tolera, segundo o abade de Cluny, numerosas outras salvaguardas tão eficazes e válidas quanto o próprio trabalho. Uma ocasião a mais para torcer, quase em zombaria, o literalismo cisterciense, ao qual Pedro dedica uma voluntária inquietude de saber se todos os modos de combate à otiositas são feitos conforme a regra e concorda que, se a otiositas é bem evitada, a regra é, seguramente, bem seguida, qualquer que seja o meio escolhido para evitá-la. Então, ao contrário, se o trabalho

\footnotetext{
${ }^{15}$ ORDERIC VITAL, IV, p. 312-320: [...] Quod vero manibus nostris cotidie non laboramus plurimorum dire stimulamur redargutionibus, sed sincerum in divino cultu laborem audacter obicimus, quem ab autenticis magistris diutina divinae legis observantia olim didicimus. Dagobertus rex et Teodericus atque Carolus Magnus imperator aliique reges et augusti cenobia devote condiderunt et de suis redditibus ad victum et vestitum servorum Dei ubertim erogaverunt, multitudinemque clientum ad exteriora ministeris pleniter explendis subegerunt, monachosque lectionibus et sacris orationibus pro cunctis benefactoribus suis et cœlestibus misteriis intentos esse constituerunt. [...].
} 
manual evita ao monge de ser otiosus, ele não lhe assegura, em nenhum caso, de ser bene negotiosus ${ }^{16}$.

A maior parte destes argumentos encontra-se, sob uma forma particularmente desenvolvida, em um verdadeiro tratado contra o trabalho manual dos monges. Sobre isso, quero me deter em um segundo momento. Trata-se do terceiro livro do comentário "sobre certos capítulos da regra debatidos por alguns religiosos", redigido por volta de 1125 pelo abade de Deutz, Rupert, para o abade de Cluny e intitulado De eo quod altaris officium precellat opus manuum ${ }^{17}$. Neste pequeno tratado, que pretende, entre outras coisas, desempatar duas partes que se opõe sobre a atribuição dos respectivos lugares, na via da perfeição apostólica, a opus manuum e o altaris officium ${ }^{18}$, Rupert, favorável ao segundo, sublinha três pontos, a seus olhos, estreitamente ligados. De início, em razão do caráter prescritivo do trabalho para os monges, a urgente necessidade de uma justa interpretação das injunções de Bento sobre o trabalho manual, em particular, tendo em vista sua compatibilidade ou não com as outras instruções de Bento nesta mesma regra e, notadamente, tudo isso que trata da opus Dei e do respeito ao claustro ( 88 e 13) ${ }^{19}$; em seguida, o papel do sacerdócio na vida monástica, particularmente, no que concerne ao delicado silêncio de Bento a este propósito, silêncio que alguns monges da época aproveitariam para esquecer seu ofício sacerdotal em proveito do trabalho manual (§ 2 e 9); enfim, os direitos dos monges-sacerdotes em viver dos rendimentos do altar e dos dízimos, que os poupava de outros modos de subsistência, como o trabalho manual (§ 10-13). Sem entrar no detalhe do conjunto da argumentação, sublinha-se a proximidade entre os argumentos e os exemplos escolhidos por Rupert e aqueles de Orderic Vital ou de Pedro o Venerável. Bento, afirma Rupert no § 5, não

\footnotetext{
${ }^{16}$ Pedro o Venerável, carta 28 a Bernardo de Claraval (1127-1128), 8 . ponto (In: CONSTABLE, 1967, p. 54 e 70-71).

${ }_{17}$ RUPERT DE DEUTZ. De eo quod altaris officium precellat opus manuum (v. 1125). In: PL 170, col. 511-526. Sobre Rupert, eu me remeto a John H. Van Egen (1983) e a Emmanuel Bain (2014, p. 104-111).

${ }_{18}$ RUPERT DE DEUTZ, § 4 (PL 170, col. 513): Inter partes diversa sentientes sese immittit hic sermo, dijudicare audens, utra pars firmius fundamentum rationis habeat: illa, quae praefert opus manuum secundum ordinationem Regulae beati Benedicti, et de labore manuum vivere perfectionem apostolicam esse contendit, an ista, quae servire altari, et de altari vivere melius esse asserit. A questão do caráter apostólico do trabalho é retomada no $\S 9$.

${ }^{19}$ Sublinha-se, aliás, somente os monges que Rupert atribui um dever de trabalho, a saber, os monachi illitterati, que devem ajudar por seu trabalho os padres, o devem realizar intus dumtaxta, intra claustra monasterii sicut supra memorata sententia B. Benedictum velle demonstravit (PL 170, col. 516). Sobre a clausura em Rupert, ver Cécile Caby (2015).
} 
fez do trabalho manual - entendido como o trabalho agrícola ${ }^{20}$ - um preceito, mas uma permissão, um patientiae consilium, o que implicava que não era necessário para a salvação. Isso permite a Rupert deslocar o centro do problema, como fez o abade de Cluny, do que a regra prescreve em matéria de trabalho manual (quid de opere manuum regula precipiat) para o porquê dela o fazer (quare). Ora, a resposta é simples: o trabalho é prescrito na regra como remédio à otiositas (§ 8) e como meio lícito de se nutrir em caso de necessidade ( $\S 6$ : ...ubi necessitas loci aut paupertas exigit). Em definitivo ( $(7)$, o trabalho manual é somente um remédio à pobreza (pauperitatis solatium) onde falta o necessário ${ }^{21}$; em todas as outras situações, Rupert eleva um paradigma econômico que é aquele de uma economia tradicional do Dom, fundada sobre a circulação dos dons materiais e espirituais, suficientemente comparável àquele que Orderic atribui aos monges de Molesmes que se opuseram a Roberto. Os dons dos grandes, dos reis e dos imperadores tinham por função evitar que os monges trabalhassem para obter sua subsistência e para lhes permitir que se consagrassem à sua vocação autêntica, aquela da prece (notadamente eucarística), pela qual os dons materiais são transformados em dons espirituais. Os argumentos de Rupert são de duas ordens: de uma parte, argumentos históricos, especificamente os modelos das funções de Gregório o Grande e de Mauro, o primeiro discípulo de Bento na Gália (um exemplo estratégico, igualmente escolhido por Pedro o Venerável); de outra parte, argumentos das escrituras sobre a base da exegese do Sl.103, 17, em virtude do qual os monge são como os pássaros do céu, tanto como os Grandes, que constroem e dotam os mosteiros, são o cedro do Líbano em cujos galhos os monges edificam seus ninhos ${ }^{22}$. Conforme a este modelo

\footnotetext{
${ }^{20}$ RUPERT DE DEUTZ, § 5 (PL 170, col. 513-514): De illo opere manuum, quo maxime victus acquiritur, quod est arare, seminare et metere, silvasque succidere, perspiccum est quia non est beati Benedicti preceptum; ou mais adiante: labores agrorum sive opera in agris. Isso deixa a porta aberta a outras formas de "trabalho", mais compatíveis com as outras obrigações da regra.

${ }^{21}$ PL 170, col. 515A.

22 PL 170, col. 515C; Rupert utiliza a mesma citação na Vita Heriberti, capítulo 12. Citado e comentado por Emmanuel Bain (2014, p. 104106) e o mesmo tipo de comentário a propósito de Mateus 6, 26 (Respicite volatilia cæli, quoniam non serunt, neque metunt, neque congregant in horrea: et Pater vester cælestis pascit illa) que ele comenta em eco ao Salmo 103, 17 (illic passeres nidificabunt, erodii domus dux est eorum) en ces termes Domus huius Erodii uita est apostolica quam ipse magister uester Christus exstruxit. Si passeres esse cupitis, si relictis omnibus, hunc magistrum sequi uultis, domus eius dux erit omnium uestrum, euangelium eius praecedit uolatum uestrum, clamans ad ligna campi, dicens ad cedros Libani, praecipiens potentibus et diuitibus huius saeculi: Expandite ramos uestros, et suscipite passeres istos, effundite thesauros uestros, et pascite uoluntarios pauperes istos. Nidificent apud uos passeres isti, construite coenobia, fundate ecclesias, ubi habitent pauperes isti, ut uacet illis uespere et mane et meridie narrare, et annuntiare, et exaudiet Deus uocem eorum, tam pro uobis quam pro semetipsis clamantium atque exorantium. (In: HAACKE, 1979, p. 181-182; cf. BAIN, 2014, p. 107110).
} 
social, a prece e o serviço do altar são os meios específicos e próprios aos monges de combater a otiositas, bem mais que o trabalho manual, que os pressionaria, ao contrário, a entrar em contradição com a regra ou com o autêntico modelo apostólico da vida monástica. De fato, para Rupert, a perfeição apostólica dos monges não reside no pretendido mérito de uma imitação do modo de vida laborioso dos apóstolos: se Paulo trabalhava, era por necessidade, em razão da avareza dos Coríntios (§ 6). A perfeição dos monges reside mais na sua capacidade de acumular profissão religiosa e ordem sacerdotal (§ 9): in his autem qui monachi simul, et clerici sunt, apostolica perfectio est ${ }^{23}$. É nesse sentido que o serviço do altar, que define a ordem sacerdotal, é igualmente um elemento da perfeição dos monges que é a melhor occupatio ( $\S 13$ ), preferível ao trabalho manual para vencer a otiositas e para, globalmente, respeitar a regra.

\section{Pobreza voluntária, trabalho manual e redistribuição}

Destacar-se-á que este modelo de função social dos monges, fundado sobre seu acúmulo do estado monástico e da ordem sacerdotal é precisamente aquele que é contestado pelos principais adversários de Rupert em seu tratado, os Cistercienses, que ele identifica por dois traços distintivos: seu literalismo em face da regra, que não lhes permite levar em conta o contexto histórico da Igreja, notadamente o fato de que - Rupert sublinha, mas também os opositores a Roberto no texto de Orderic - os monges de hoje não são aqueles do Egito (§ 11); sua reivindicação de pobreza voluntária, que Rupert não desaprova como tal (non voluntariam paupertatem tuam improbando seu contemnendo), mas da qual ele recusa a prática particularmente a do trabalho manual - e à qual ele prefere, de todo modo, na hierarquia dos critérios identitários do monge, a opus Dei e o servitio altaris $(\S 13)^{24}$.

\footnotetext{
${ }^{23}$ PL 170, col. 517. Eu partilho todos estes pontos com a análise de Bain (2014, p. 108-109).

${ }^{24}$ Sobre a pobreza, voluntária mente se tomará como ponto de partida Bain (2014, p. 77-154, em parte, 110) para o comentário da citação de Rupert.
} 
Ora, as questões do modelo de Rupert ou de sua recusa são extremamente concretas e explicam, sem dúvida, o vigor das polêmicas. É suficiente, para se convencer disso, se deter um instante nos efeitos induzidos a propósito dos dízimos. Se, de fato, a uma função é associado um tipo de rendimento, recusar aos monges o ofício de sacerdote implica em lhes negar igualmente os rendimentos dos dízimos e, globalmente, os do altar. De fato, os Cistercienses (e outros com eles) os recusam em bloco (Cf. CONSTABLE, 1964 e CABY, 2012.). Aquilo não significa, em todo caso, que eles coloquem em causa o primado fundiário da subsistência monástica e então, a propriedade monástica, nem que eles recusem totalmente o princípio dos dons e da circulação virtuosa entre dons materiais dos laicos e as preces dos monges, mesmo que eles coloquem importantes freios às práticas de comemoração dos defuntos $^{25}$ e limitem drasticamente o alcance dos laços com os laicos criados pelo sistema do Dom. Na realidade, os Cistercienses se esforçam por propor outra lógica do Dom que libera idealmente o monacato de toda relação com o mundo secular as terras dos laicos se tornam terras dos monges tidas em plena propriedade, fora de toda reivindicação dos herdeiros e de eventuais co-possessores ${ }^{26}$. Uma lógica de austera autossubsistência a escala da comunidade dos monges e dos conversos, que se aparta igualmente das formas clunisianas de exploração do trabalho do outro que não são os conversos que os textos normativos integram à família, distinguindoos - e da mendicância eremítica ${ }^{27}$; uma economia produtora certamente, mas não acumuladora, pois pensada em função de seu consumo e de sua redistribuição caritativa $^{28}$; uma economia alimentada pelo trabalho manual dos membros da família rigorosamente regida em seu horário e em suas modalidades concretas ${ }^{29}$.

\footnotetext{
${ }^{25}$ Sobre os costumes comemorativos cistercienses, ver: Guido Cariboni (2005b).

${ }^{26}$ Ver as proposições muito estimulantes de Martha G. Newman (1996, p. 70-82 e notas, p. 284-291).

${ }^{27}$ A este propósito, ver o sermão 50, § 16 d'Isaac de l'Étoile (1987, p. 192-193) que opõe mendicantes (pobres reais ou eremitas?) e os especialistas da captação dos dons. Sobre a virada em relação à esmola, por exemplo, junto a Estevão de Muret, conferir Bain (2014, p. 98-100).

${ }^{28} \mathrm{Ver}$, por exemplo, o sermão de Bernardo contra os eclesiásticos que entesouram os alimentos dos pobres, citado por Giacomo Todeschini (2004, p. 33) ou os § 13 e 19 do sermão 50 de Isaac de l'Étoile (1987, p. 188-191, 194-195), mas também as críticas de Geoffroy de Auxerre em um sermão sobre a multiplex paupertas nostra, contra o trabalho que se convertia em fonte de riqueza (GASTALDELLI, 2001, p. 522-530 e 542-548; Cf. PAULITTI, 2004, p. 207-228).

${ }^{29}$ Ver, por exemplo, os capítulos 75 (De labore) e 84 (De tempore secationis et messionis) dos Ecclesiastica Officia sobre o trabalho e a colheita (In: CHOISSELET \& VERNET, 1989, p. 218-225, 242-245; cf. FRANCE, 2012, p. 41). Isaac de l'Étoile (Sermão 50, § 15) insiste sobre o fato que o justo modo de vida implica de viver de seu próprio trabalho, daquele dos familiares e da criação de animais.
} 
Quanto aos dízimos, recusados a título de officium altaris (que não releva dos monges, segundo os Cistercienses), eles podem, em compensação, ser aceitos, às vezes, em nome da pobreza voluntária, reivindicados sobre os frutos das terras trabalhadas pelos monges - em seguida daquelas que são cultivadas a seus custos e por seus assalariados. Em suma, para simplificar, tudo se passa como se o trabalho manual, nascido como uma solução para compensar a perda consecutiva resultante da recusa em receber certos rendimentos, notadamente os dízimos, se tornasse o principal marcador de uma pobreza voluntária identitária, que justifica (por um princípio de reciprocidade) o não pagamento dos dízimos sobre as terras cultivadas pelos pauperes Christi. Como o mostra a terminologia dos privilégios pontificais a partir dos anos 113030, os Cistercienses conseguiram, belo e bem, apoderar-se, em seu proveito, da distinção - que eles não eram, na realidade, os primeiros, nem os únicos a empregar31 - entre os frutos do trabalho de suas próprias mãos e os do trabalho do outro, para erigir em uma sorte de oposição estruturante entre eles mesmos e o resto do monacato.

Parece-me essencial, neste ponto, sublinhar o sentido produtivo que se revestiu, progressivamente, no curso dos debates, a noção de labor, entendido, às vezes como esforço e fadiga corporal e, a este título, como suporte de todas as interpretações em termos de penitência e de ascese, mas também como produto desta fadiga, assegurando a autonomia dos monges, às vezes, sua autarquia em relação aos laicos, doadores, mas também aos laboratores cujo trabalho é

\footnotetext{
${ }^{30}$ Conferir os privilégios Sane laborum vestrorum, quos propriis manibus colitis, sive de nutrimentis animalium exigere vel extorquere presumat, concedidos a Citeaux e depois a Claraval por Inocencio Il em 1132 (10 de fevereiro e 17de fevereiro, PL 179, col. 123 e 126).

${ }^{31}$ Destacar-se-á, por exemplo, o modo como Abelardo, na carta 8 a Heloisa, crítica os "moines qui s'exposent aux plus graves tourments et à la plus grande servitude, en se soumettant à la tutelle des puissance laïques ou ecclésiastiques, espérant pouvoir vire dans la paresse (otiose) et être nourris du travail d'autrui (de alieno victitare labore) ; ils en viennent ainsi à perdre et le nom de moine - c'est-à-dire de solitaire - et l'essence même de la vie monastique" (ABÉLARD \& HÉLOISE, 2007, p. 376-567, em parte, 402-403; cf. CABY, 2015, p. 123124). Ver, igualmente, o sermão 33 sobre João Batista (In: ABÉLARD, 1849 p. 566-592, em parte, 572: lam quippe refrigescente, immo extincto religionis feruore, postmodum de labore proprio vivere deberemus, quod unum vere monachos efficere beatus Benedictus meminit, inimicam animae sectantes otiositatem, de alieno labore victum quaerimus: et huius noxiae quietis perversa libertate utentes, et tam luxui rerum quam multiloquio uacantes, veram praedicti onagri libertatem amisimus. Unde saecularibus nos implicantes negotiis, dum cupiditate terrenorum nobis dominante, ditiores fieri studemus in monasterio quam fueramus in saeculo, terrenis nos dominis potius quam Deo subiecimus. Villas et homines et servos pariter et ancillas a potentibus saeculi tamquam in eleemosyna sumentes, eorum nos gravi iugo subiugamus, et nonnunquam pro paucis quae accipimus multa persoluimus. Quae cum de suo potius quam de nostro sibi provenire censeant, nullas his habent grates, quae sibi non tam dari quam reddi autumant. Sobre este sermão e seus pontos comuns com a carta 8, conferir J. Miethke (1973, em parte, 177-181) e Bain (2014, p. 111-117).
} 
idealmente e, em certas ocasiões, na prática, repelido para fora das terras dos monges ${ }^{32}$. Como o resume o canonista Estevão de Tournai, em uma carta ao abade de Pontigny (1178-1180), em forma de verdadeiro elogio da Ordem Cisterciense e que retoma a maior parte dos traços do sermão 50 de Isac de l'Étoile, a pobreza dos Cistercienses é santa nisto que ela os garante do frio e da fome sem os constranger à mendicidade ou à adulação dos grandes, desde que eles obtém sua nutrição e sua vestimenta do trabalho de suas próprias mãos; do mesmo modo, eles honram a Deus e à caridade quanto ao próximo com seus próprios frutos33.

\section{Conventum metentium monachorum: o mosteiro nos campos}

Este conjunto de práticas ou, mais ainda, de elementos do discurso que as designam, se tornam, muito rapidamente - aí compreendido ao exterior da ordem, como sublinha a cronologia discernida nos textos de Orderic Vital e de Rupert de Deutz - uma sorte de marcador identiário da especificidade e da distinção cisterciense e um sinal exterior do pertencimento ou da adesão à nebulosa cisterciense, mesmo em uma data onde alguns laços institucionais não eram perfeitamente formalizados, o que é muito nítido no quadro que o autor dos Milagres de Nossa senhora de Laon esboçava, por volta de 1150, das monjas de Montreuil ocupadas com os mais duros trabalhos nos campos (HÉRIMAN, 2008, § 17 , p. 234-

\footnotetext{
${ }^{32}$ A crítica anti-cisterciense ao enriquecimento dos Cistercienses pela via do trabalho vai no mesmo sentido, como o sublinha as famosas palavras de Gauthier Map (De nugis curialium, I, 24), mas também com um sermão de Estevão de Tournai, recentemente editado (Clamant coloni expelli sese de agris suis, clamant ecclesiæ spoliari se decimis suis: cf. DOLVECK, 2013); relevar-se-á o modo como Isaac de l'Etoile se defende no semão 50, § 13: ...quare in laboribus tanta est corporis exercitatio tanta in acquirendis rebus negotiatio ? Quoniam qui ideo multum laborat et multum acquirit ut multum vescatur, ventri suo tantum servit et illi soli negotiator ergo et sit unde tribuatur necessitatem patienti, ut alii possint in labores nostros aut nobiscum aut post nos introire (In: ISAAC DE L'ÉTOILE, 1987, p. 189191).

${ }_{33}$ Carta 71 de Estevão de Tournai a Robert de Pontigny (PL 211, col. 361-370, em parte, 362; DESILVE, 1893, p. 5-6; cf. TODESCHINI, 2004, p. 35-36): Cisterciensium ordinem, quasi lucernam supra montem positam, quis in Ecclesia Dei maximum et praecipuum culmen non dicat attingere? Evangelium implentes, monasticam regulam quam supererogavit Benedictus pater, fidelis Samaritani stabularius, sic observant, ut nec unum ex ea iota preterire videantur. Beata paupertas eorum, que licet eos fame premat et frigore, non tamen aut mendicare compellit, aut divitibus adulari. Suis aut suorum manibus victum adquirunt et vestitum, non veriti sequi Paulum, qui, cum licite posset de evangelio vivere et, spiritualia seminans, carnalia metere, maluit tamen manibus suis operari, ne quod offendiculum daret Evangelio Christi. Honorant Dominum de sua, non de aliena substantia, et de primitiis frugum, non alterius, sed suarum dant pauperibus: quanquam rectius non sua, sed omnium dixerim que universis secundum gradus ordinate caritatis quasi in commune deserviunt; neque enim buccellam suam comedunt soli et non comedit cum eis pupillus ex ea. Sobre a relação entre o trabalho, a mendicância e a adulação dos ricos, ver o sermão 50, § 18 de Isaac de l'Étoile (1987, p. 192-195) onde a exegese de Mt 6, 26 é quase revertida, pois se o Senhor nutre bem os pássaros, admite Isaac "mais tout de même ils importunent les hommes en guettant les labours", mas também o sermão 33 de Abelardo, citado na nota número 31, e Hugo de Fouilloi, De claustro anime (após1132), II 9 De iis, qui vagi et otiosi fratribus laborantitibus detrahunt (PL 176, col. 1057).
} 
235). Esta descrição é particularmente emblemática como um dos pontos sobre os quais os Cistercienses modularam rapidamente seu propositum para adaptá-lo às mulheres: precisamente, a obrigação do trabalho manual, de fato, incompatível com as exigências - consideradas como absolutamente prioritárias no caso das mulheres - da clausura no mosteiro34.

A natureza deste último texto nos conduz a valorizar o papel, na construção de uma representação renovada do trabalho no seio da Ordem Cisterciense, de outro conjunto textual composto quase exclusivamente de exempla ou de Vitae, logo, de textos hagiográficos elaborados na Ordem Cisterciense (em primeiro lugar, no movimento de Claraval) entre a segunda metade do século XII e 1220; que contribuem com os textos normativos citados anteriormente e com as exortações das cartas e dos sermões, para construir uma identidade econômica compartilhada na Ordem Cisterciense e para institucionalizar, em seu seio, a prática do trabalho manual35. Na expectativa de um exame mais aprofundado e, em particular, de um recenseamento mais exaustivo dos relatos que colocam em cena os Cistercienses (monges e conversos) no trabalho36, desejo, de imediato, evidenciar um dos principais motivos em torno dos quais se articula nestes relatos - como nos sermões contemporâneos - o esforço empreendido pela Ordem para construir um modelo hagiográfico do trabalho manual, a saber, o motivo comunitário. Pode-se, a este propósito, se apoiar sobre as numerosas redações - indício de um grande sucesso e de uma ampla difusão na Ordem - do famoso exemplum da Virgem que visita os Cistercienses que trabalham nos campos 37 . Ao curso da colheita, um monge, que se afastou temporariamente do grupo, teve a visão de duas ou três mulheres de um aspecto extraordinário, que faziam visitas e caminhavam entre os irmãos no

\footnotetext{
${ }^{34}$ A propósito da afiliação das comunidades femininas à ordem cisterciense no século XII, tomar-se-á como ponto de partida os finos balanços de Alexis Grelois (2009, p. 287-324; 2012, p. 141-186).

${ }^{35}$ Sobre a articulação estreita entre textos normativos, hagiográficos e exemplares, tomar-se-á como ponto de partida numerosos artigos de B. P. McGuire citados por Cécile Caby (2003, n. 33, p. 250) e Stefano Mula (2010).

${ }^{36}$ Encontra-se um primeiro florilégio muito parcial e traduzido de modo muito livre em Anselme Dimier (1982-1987, particularmente, p.572-574); James France (2012, p. 325-332) propôs igualmente um primeiro percurso sobre estes textos (p. 41-44), assim como uma lista dos exempla que colocam em cena conversos; mas todos não abordam o trabalho manual e, sobretudo, estão bem longe de cobrir os exempla relativos a este tema, muito frequente a propósito dos monges.

${ }^{37}$ Para uma primeira abordagem (e um primeiro levantamento das diferentes versões) ver: McGuire (1983, p. 39-41), Mula (2010, p. 189, n. 14) e France (2012, p. 42-43) que sublinha alguns elementos de variação, principalmente quanto à presença ou ausência de conversos.
} 
trabalho; ele teve, em seguida, a revelação de que se tratava da virgem acompanhada das santas Elisabeth e Maria Madalena. B. P. McGuire e Stefano Mula já sublinharam o modo que este exemplum encena o amor singular e a proteção especial da Virgem quanto aos Cistercienses ou aos monges de Claraval, onde se situou a anedota nas três principais versões do exemplum - a Collectaneum Claravallense (IV 16), o Liber Miraculorum (I 1) de Herbert de Torrès e o Dialogus Miraculorum (I 17) de Cesário de Heisterbach, o qual se afirmava ter sido convertido à Ordem após ter ouvido este exemplum ${ }^{38}$.

B. P. McGuire tem, por outro lado, evidenciado bem a evolução do sentido dado ao exemplum entre o final do século XII e o primeiro terço do século XIII: se as primeiras versões, como, por exemplo, aquela do Collectaneum de Claraval, interpretam explicitamente a visita sob o modelo da proteção senhorial - a Virgem e seus acólitos andam no meio dos irmãos como o fazem habitualmente os emissários dos senhores para protegê-los de toda fraude exterior39 - é, em seguida, somente a proteção mariana que é exaltada. Parece-me, não menos, que é possível acrescentar dois elementos de interpretação que tratam com mais justiça o lugar do trabalho dos irmãos na economia do relato. De início, notar-se-á que todas as versões do relato insistem na coesão, nos campos, da comunidade unida no trabalho pela obediência comum, pela penitência e, enfim, pelo despojamento do velho homem. Isto implica que ricos e pobres, superiores e sujeitados trabalhem lado a lado e do mesmo modo. Segundo Herbert de Torrès, o monge visionário, antes mesmo da visão, já está feliz pelo espetáculo dos monges - letrados, nobres ou delicados - que trabalham duramente como se eles se encontrassem nas delícias ou em um banquete40. Ora, independentemente da interpretação paradisíaca própria a este

\footnotetext{
${ }^{38}$ Collectaneum exemplorum et visionum Claraeuallense de João de Claraval (Troyes, Bibl. Municipale, ms 946), IV, 16 (In: LEGENDRE, $\mathrm{n}^{\circ}$. 90, 2005, p. 289); Herbert de Torrès, Liber miraculorum versão breve (final dos anos 1170), I 1, PL 185, col. 1273A-1276D ; Cesário de Heisterbach, Dialogus Miraculorum I 17 (In: STRANGE, 1851, I, p. 24-25).

${ }^{39}$ ut solent se habere deputati a dominis suis eo tempore homines seculares ad custodiam messorum. Et reuera custodiebant eos, non ut de fraude frugum suspectos eos haberent, sed ne inuisibiles fraudatores sanctorum laborum fructui per aliqua temptamenta frau dem inferre presumerent

${ }^{40} \mathrm{PL}$ 185, col. 1274 : ... secum reputans pariter et admirans, quia videlicet tot sapientes, tot nobiles et delicati ibidem viri, propter amorem Chrsiti laboribus atque aerumnis seipsos exponerent, et ferventissimum solis illius ardorem cum tanta alacritate susciperent, acsi protensis in horto delciarum suavissime flagrantia poma decerperent, vel in mensa lautioribus epulis plena deliciosissime convivarent.
} 
relato e à qual é frequentemente preferido uma interpretação quase martirial dos sofrimentos dos trabalhadores, este tipo de descrição da comunidade no campo não está isolado, ao contrário, na literatura cisterciense, notadamente, na hagiografia41. Em segundo lugar, me parece que é possível reconhecer, nos detalhes do relato, certo número de respostas à objeção - frequentemente sublinhada pelas polêmicas anticistercienses e sem dúvida consideradas muito seriamente pelos Cistercienses - da incompatibilidade do trabalho com a regra, notadamente em razão da contradição entre a realização do trabalho manual, sob a forma do trabalho agrícola nos campos, e a interdição de sair dos muros monásticos (RB 66, 6)42. De fato, em suas diversas versões, a descrição do modo como a Virgem e seus acólitos andam lentamente no meio do conventum metentium monachorum e circulam com reverência (circuire) remete-se ao deslocamento circular dos rituais de consagração (MÉHU, 2008.). Tudo se passa como se o relato sobrepusesse a função primordial de proteção da Virgem e de seus acólitos a uma função de sacralização do convento e dos irmãos trabalhadores: é, em definitivo, todo mosteiro que se transporta nos campos e aí é visitado, protegido e consagrado pela Virgem de maneira visionária ou onírica, que não está distante de alguns relatos de fundação da Ordem (CABY, 2009). Desse modo, não somente os campos cultivados podem aparecer sob os traços de um jardim paradisíaco - como o sugere a alusão ao pomar ou ao banquete nas versões de Herbert e do Grande Exórdio - mas é igualmente criada uma continuidade espacial entre o mosteiro enclausurado e a comunidade monástica nos campos, o que resulta na contradição entre trabalho manual e ruptura do claustro43.

\footnotetext{
${ }^{41}$ Sobre este ponto, ver, por exemplo, a descrição do trabalho dos monges de Claraval em uma carta de Pedro de Roye a um amigo (PL 182, col. 711-712), mencionada e traduzida por Dimier (1982-1987, p. 569); igualmente, ver a Vida de Amédée de Bonnevaux (DIMIER, 1963).

${ }^{42} \mathrm{~A}$ este propósito, notar-se-á que 3 das 4 ocorrências de termini (parte externa dos muros do espaço monástico) em Ecclesiastica officia encontra-se no capítulo 75 de labore, citado na nota 27.

${ }_{43}$ Para comparação, ver a Parábola de Galand de Regny, 5 (GALAND DE REGNY, 1992, p. 103-113); cf. Caby (2015, p. 145).
} 


\section{Conclusão}

Para concluir, desejo voltar a dois aspectos complementares. Um deles, que me parece essencial a propósito da questão do trabalho dos Cistercienses, tal como o tinha rapidamente apresentado aqui, é o modo que, em todos os casos, se percebe a impossibilidade de separar a elaboração concreta de um modelo econômico da parte dos monges de seus discursos eclesiológicos, na medida em que aqueles questionam ou constroem a função monástica na sociedade ao sabor de uma multidão de tipologias textuais que não exclui os documentos da prática, ao contrário. Deste ponto de vista, a virada dos séculos XI e XII é, através do novo monacato, portadora de um novo paradigma transmitido tanto pelas cartas (e suas re-escrituras nos cartulários e nas pancartes), quanto pelos textos narrativos, das homilias ou das hagiografias e que se inscreve sobre o terreno através do novo desenho das paisagens. Por todos estes meios, os Cistercienses, se eles não rompem com a imagem ascética e penitencial do trabalho, o enriquecem claramente de um valor positivo, a serviço de uma maior perfeição comunitária.

Este enriquecimento passa, em particular, pela ampliação da função do trabalho manual dos monges, aí compreendido em relação com a regra de Bento, pois que não releva mais somente da ordem da necessidade vital - o que Rupert se esforçava por limitar no passo da depreciação global do trabalho agrícola do monacato pós-carolíngio, mas também em eco das exigências do respeito à regra, reivindicado pelos Cistercienses, e que Rupert lhes contesta sobre este ponto, particularmente -, mas também de outras funções como aquela da redistribuição e da busca comunitária pela perfeição na unidade e na autarquia. Uma busca que se afasta de outros modelos de subsistência ascético que excluem o trabalho corporal e se apoiam, segundo a terminologia cisterciense, no trabalho do outro: o modelo clunisiano ou 'rupertiano' - da renda fundiária ou aquele - eremítico - da mendicância, igualmente condenados como fonte de escravidão. Logo, sem corresponder a uma renovação total da percepção do trabalho humano como atividade, principalmente - e a fortiori exclusivamente- produtiva, os debates 
monásticos do século XII, confirmando, em suma, a função penitencial primordial do trabalho, não abrem menos a via para uma nova elaboração do sentido do trabalho manual pelo viés de seu valor ético no quadro comunitário.

\section{REFERÊNCIAS}

ABÉLARD, Peter. In: COUSIN, V.; JOURDAIN, C.; DESPOIS, C. Petrus Abaelardus Opera, t. I, Paris, 1849. Hildesheim: Georg Olms Verlag, 1970.

ABÉLARD, Peter; HÉLOISE. Lettres d'Abélard et Héloïse. Paris: Librairie générale française, 2007.

AELREDUS RIEVALLENSIS. Collectiones Claraeuallensis Prima, Claraeuallensis Secunda et Dunelmensis, Collectio Radingensis, Sermones Lincolnienses, Sermo LXXIX a Matthaeo Rieuallensi Seruatus In: RACITI, G. (éd.). 3 vols. Turnhout: Brepols, 1989, 2001, 2012.

ARNOUX, Matthieu. Le temps des laboureurs. Travail, ordre social et croissance en Europe (11e-14e siècle). Paris: Albin Michel, 2012.

BAIN, Emmanuel. Au paradis pour travailler ? Le travail d'Adam au paradis à l'époque romane. In: FRAY, S.; MOREL, D. La terre à l'époque romane. Exploitations, usages et représentations. Actes du colloque d'art roman d'Issoire (2014). Clermont-Ferrand: Alliance Universitaire d'Auvergne: 2016, p. 175-192.

BAIN, Emmanuel. Église, richesse et pauvreté dans l'Occident médiéval. L'exégèse des Évangiles aux XIIe-XIIIe siècles. Turnhout: Brepols, 2014.

BECK, Patrice (dir.); BERNARDI, Philippe (dir.); FELLER, Laurent (dir.). Rémunérer le travail au Moyen Âge: pour une histoire sociale du salariat. Paris: Picard, 2014.

BELL, David N. "In manibus suis": Guillaume de Saint-Thierry, les Pères du Désert et la spiritualité du travail manuel. In: Signy-l’Abbaye : Site cistercien enfoui, site de mémoire et Guillaume de Saint-Thierry (actes du colloque international d'études cisterciennes, 9-11 sept. 1998). Signy : Association des Amis de l'Abbaye de Signy, 2000, p. 475-485.

CABY, Cécile. Comme un poisson dans l'eau... Propositum vitae et lieux de vie monastique (xie-xiie siècle). In: LAUWERS, Michel (dir.). Monastères et espace social dans

l'Occident médiéval. Genèse et transformation d'un système de lieux dans l'Occident médiéval. Turnhout: Brepols, 2015 (Collection d'études médiévales de Nice, 15), p. 323358.

CABY, Cécile. Couvents et espaces religieux chez Géraud de Frachet et Bernard Gui. Une topographie légendaire des origines dominicaines? In: Moines et religieux dans la ville (XIIe-XVe siècles). Toulouse: Privat, 2009 (Cahiers de Fanjeaux 44), p. 357-388. 
CABY, Cécile. De l'abbaye à l'ordre: écriture des origines et institutionnalisation des expériences monastiques, XIe-XIIe siècles. In: La mémoire des origines dans les institutions médiévales. MEFRM - Mélanges de l'École française de Rome - Moyen Âge, Roma, v. 115, n. 1, 2003, p. 235-267.

CABY, Cécile. Les moines et la dîme (xie-xiiie siècle). Construction, enjeux et évolutions d'un débat polymorphe. In: LAUWERS, Michel (dir.). La dîme dans l'Occident médiéval. Prélèvement seigneurial, Église et territoires. Turnhout: Brepols, 2012 (Collection d'études médiévales de Nice, 12), p. 361-401.

CARIBONI, Guido. "Il nostro ordine è la carità". Osservazioni sugli ideali, i testi normativi e le dinamiche istituzionali presso le prime generazioni cistercensi. In: ANDENNA, Cristina (éd.); MELVILLE, Gert (éd.). Regulae - Consuetudines - Statuta. Studi sulle fonti normative degli ordini religiosi nei secoli centrali del Medioevo. Münster: LIT Verlag, 2005a, p. 277-310.

CARIBONI, Guido. La memoria dei vivi e dei morti presso i Cistercensi. In: BORGOLTE, M. (éd.); FONSECA, Cosimo Damiano (éd.); HOUBEN, Hubert (éd.). Memoria: ricordare e dimenticare nella cultura del Medioevo. Erinnern und Vergessen in der Kultur des Mittelalters. Bologne: Il Mulino/Berlin: Duncker \& Humblot, 2005b, p. 347-388.

CARIBONI, Guido. Suis propriis manibus vel sumptibus. Travail agricole, salariés et dîmes chez les Cisterciens du XIIe siècle. In : Les moines (cisterciens) et le travail au Moyen Âge. Nice : CEPAM UMR 7264, 28 mars 2014. No prelo.

CHIBNALL, Marjorie (éd.). The Ecclesiastical History of Orderic Vitalis, 5 vols. Oxford: Clarendon Press, 2002-2003.

CHOISSELET, Soeur Danièle (éd.) \& VERNET, Frère Placide (éd.). Les ecclesiastica officia Cisterciens du XIIe siècle: Texte latin selon les manuscrits édités de Trente 1711, Ljubljana 31 et Dijon 114, version française, annexe liturgique, notes, index et tables. Reiningue: Abbaye d'Oelenberg, 1989.

CONSTABLE, Giles (éd.). The Letters of Peter the Venerable. 2 vols. Cambridge (Mass.): Harvard University Press, 1967.

CONSTABLE, Giles. Monastic tithes from their origins to the Twelfth century. Cambridge: The University Press, 1964.

CONSTABLE, Giles; SMITH, B. Libellus de diversis ordinibus et professionibus qui sunt in aecclesia. Oxford: Clarendon Press, 1972.

DESILVE, Jules (éd.). Lettres d'Étienne de Tournai. Paris: A. Picard, 1893.

DEVROEY, Jean-Pierre. Mobiles et préoccupations de gestion dans l'économie monastique du monde franc. Revue bénédictine, Bélgica, v. 103, n. 1-2, 1993, p. 224-240.

DIMIER, Anselme (éd.). Vita venerabilis Amedaei Altae Ripae. In: Studia monastica, Barcelona, v. 5, 1963, p. 265-304. 
DIMIER, Anselme. Le travail chez les premiers cisterciens. In: CHAUVIN, B. (éd.). Mélanges Anselme Dimier, I/2. Arbois: B. Chauvin, 1982 - 1987, p. 565-574.

DOLVECK, Franz. Le diable convole: un sermon inédit d'Etienne de Tournai pour la Pentecôte. In: Archives d'histoire doctrinale et littéraire du Moyen Âge, v. 80, n. 1, 2013, p. 123-146.

DUBOIS, Jean. Le travail des moines au Moyen Âge. In: HAMESSE, Jacqueline; MURAILLE-SAMARAN, C. (dir.). Le Travail au Moyen Âge: une approche interdisciplinaire : Actes du Colloque international de Louvain-la-Neuve, 21-23 mai 1987. Louvain-la-Neuve : Univ. catholique de Louvain, 1990, p. 61-100.

FRANCE, James. Separate but equal: Cistercian lay brothers, 1120-1350. Collegeville (Minn.): Liturgical Press , 2012 .

GALAND DE RÉGNY. Parabolaire. Paris: Le Cerf, 1992 (SC 378).

GASTALDELLI, Ferruccio. Studi su San Bernardo e Goffredo di Auxerre. Firenze : SISMEL-Edizioni del Galluzzo, 2001 (Millennio medievale 30).

GRELOIS, Alexis. Abbé-père et abbesse-mère : Noirlac, L'Éclache et leur fondation de Bussière (vers 1188-1238). In: Cîteaux - commentarii cistercienses, Bélgica, 2012, p. 141-186.

GRELOIS, Alexis. L'expansion cistercienne en France: la part des affiliations et des moniales. In: FELTEN, Franz J.; RÖSENER, Werner (ed.). Norm und Realität. Kontinuität und Wandel der Zisterzienser im Mittelalter. Berlin: Lit, 2009, p. 287-324.

HAACKE, Hrabanus (éd.). Ruperti Tuitiensis. De Gloria et Honore Filii Hominis super Mattheum. Turnhout: Brepols, 1979 (CCCM 29).

HÉRIMAN DE TOURNAI. Les miracles de sainte Marie de Laon. Paris: CNRS Éditions, 2008 (Sources d'histoire médiévale publiées par l'IRHT, 36).

HERIMANNUS ABBAS. Liber de Restauratione Ecclesie Sancti Martini Tornacensis. Turnhout: Brepols, 2010 (CCCM, 236).

HOLDSWORTH, Ch. J. The Blessing of Work: the Cistercian View. In: BAKER, Derek (éd.). Sanctity and Secularity: the Church and the World. Oxford: Basil Blackwell, 1973: 1973, p. 59-76.

HUYGENS, R. B. C. (éd.). Hériman de Tournai, Liber de restauratione ecclesie sancti Tornacensis. Turnhout: Brepols, 2010 (CCCM, 236).

ISAAC DE L'ÉTOILE. Sermons 40-55. Texte établi par Anselm Hoste et Gaetano Raciti. Paris: Cerf, 1987 (SC 339). 
KURZE, D. Die Bedeutung der Arbeit im zisterziensichen Denken. In: Die Zisterzienser. Ordensleben zwischen Ideal und Wirklichkeit. Köln: Rheinland-Verlag, 1980, p. 179-203.

LAUWERS, Michel. « Opus manuum » et « labor agrorum ». À propos de l'organisation socio-spatiale de la production et de l'approvisionnement des monastères dans l'Occident médiéval. In: Monachesimo d'Oriente e d'Occidente nell'alto Medioevo. Spoleto 31 marzo - 6 aprile 2016. Spoleto: CISAM, 2017a, p. 877-911.

LAUWERS, Michel. Le labeur sans la domination? Notes d'historiographie et de sémantique à propos des laboratores dans l'Occident médiéval. In: DIERKENS, Alain (éd.) ; SCHROEDER, Nicolas (éd.); WILKIN, Alexis (éd.). Penser la paysannerie médiévale. Un défi impossible. Études offertes à Jean-Pierre Devroey. Paris: Publications de la Sorbonne, 2017b.

LE GOFF, Jacques. Un autre Moyen Âge. Paris: Gallimard, 1999.

LECLERCQ, Jean. Le Travail: Ascèse sociale d'après Isaac de l'Étoile. Consommation et production. In: Collectanea Cisterciensia, Bélgica, v. 33, 1971, p.159-166.

LEGENDRE, O. (éd.). Collectaneum exemplorum ac visionum Clarevallense e codice Trecensi 946. Turnhout: Brepols, 2005 (CCCM, 208).

MC GUIRE, Brian P. A Lost Clairvaux Exemplum Found: The Liber visionum et miraculorum compiled under Prior John of Clairvaux (1171-79). In: Analecta

Cisterciensia, Roma, ano 39, 1983, p. 27-62.

MÉHU, Didier (dir.). Mises en scène et mémoires de la consécration de l'église dans l'Occident médiéval. Turnhout: Brepols, 2008.

MENANT, François. Economia monastica del Norditalia nel secolo della riforma. In: LUCIONI, Alfredo (éd.). Il monachesimo italiano del secolo XI nell'Italia nordoccidentale: atti dell'VIII Convegno di studi storici sull'Italia benedettina San Benigno Canavese (Torino). 28 settembre - 1 ottobre 2006. Césène, 2010, p. 35-48.

MIETHKE, J. Abaelards Stellung zur Kirchenreform. Eine Biographische Studien. In: Francia, Paris, v. 1, 1973, p. 158-192.

MULA, Stefano. Herbert de Torrès et l'autoreprésentation de l'ordre cistercien dans les recueils d'exempla. In: POLO DE BEAULIEU, Marie-Anne (éd.) ; COLLOMB, Pascal (éd.); BERLIOZ, JACQUES (éd.). La Tonnerre des exemples. Exempla et médiation culturelle dans l'Occident. Rennes: Presses universitaires de Rennes, 2010, p. 187-199.

NEWMAN, Martha G. The boundaries of charity. Cistercian culture and ecclesiastical reform, 1098-1180. Stanford California: Stanford University Press, 1996.

ORDERIC VITAL. In: CHIBNALL, Marjorie (éd.). The Ecclesiastical History of Orderic Vitalis, 5 vols. Oxford: Clarendon Press, 2002-2003. 
PAULITTI, Susi. Il vocabolario economico cisterciense: Bernardo di Clairvaux ed Aelredo di Rielvaux. In: TONEATTO, Valentina (éd.); ČERNIC, Peter (éd.); PAULITTI, Susi (éd.). Economia monastica: dalla disciplina del desiderio all'amministrazione razionale. Spoleto: Centro italiano di studi sull'Alto medioevo, 2004, p. 209-214.

PIRON, Sylvain. L'amélioration du monde. In : Revue de théologie et de philosophie, v. 144, 2012, p. 221-234.

ROSÉ, Isabelle. Autour des "tâches manuelles" monastiques: opus*, opera* et labor* dans quelques textes normatifs du VIe au IXe siècles. In : Séminaire À propos du «travail » au Moyen Âge. Nice, CEPAM UMR 7264, 3 avril 2015. No prelo.

SCHREINER, K. Brot der Mühsal. Körperliche Arbeit im Mönchtum des hohen und späten Mittelalters. In: POSTEL, V. (éd.). Arbeit im Mittelalter: Vorstellungen und

Wirklichkeiten. Berlin, 2006, p. 133-170.

SCHROEDER, Nicolas; WILKIN, Alexis. Documents de gestion inédits provenant de l'abbaye de Stavelot-Malmedy et concernant les domaines de Lantremange, Jenneret et Louveigné (Xe-XIIe siècle). In: Bulletin de la Commission royale d'Histoire, Bruxelles, v. 180, 2014, p. 5-48.

STRANGE, Joseph (éd.). Caesarii Heisterbacensis monachi ordinis cisterciensis Dialogus miraculorum. 2 vol. Cologne/Bonn/Bruxelles: H. Lempertz and Co, 1851.

\section{TODESCHINI, Giacomo. Ricchezza francescana: dalla povertà volontaria alla società di mercato. Bologna: il Mulino, 2004.}

TONEATTO, Valentina (éd.), ČERNIC, Peter (éd.); PAULITTI, Susi (éd.). Economia monastica: dalla disciplina del desiderio all'amministrazione razionale. Spoleto: Centro italiano di studi sull'Alto medioevo, 2004.

VAN ENGEN, John H. Rupert of Deutz. Berkeley/Los Angeles/London: University of California press, 1983.

VOGÜÉ, Adalbert de. Travail et alimentation dans les Règles de saint Benoît et du Maître. In: Revue bénédictine, Bélgica, v. 74, 1964, p. 242-251.

WADDELL, Chrysogonus. Narrative and Legislative Texts from Early Citeaux. Brecht: Commentarii Cistercienses, 1999.

WALTER MAP. De nugis curialium. In : JAMES, M. R. (éd.). Oxford : Clarendon Press, 1914 (Anecdota Oxoniensia, Medieval and modern series 6).

WILKIN, Alexis. Communautés religieuses bénédictines et environnement économique. IXe-XIIe siècles. Réflexions sur les tendances historiographiques de l'analyse du temporel monastique. In: VANDERPUTTEN, Steven (dir.); MEIJNS, Brigitte (dir.). Ecclesia in medio nationis. Réflexions sur l'étude du monachisme au Moyen Âge central. Louvain: Leuwen University Press, 2011, p. 101-150. 